\title{
Interleukin-8 activates coagulation and correlates with survival after talc pleurodesis
}

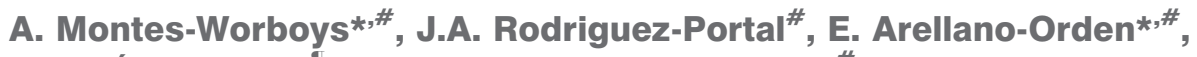 \\ J. Digón-Pereiras ${ }^{\star}$ and F. Rodriguez-Panadero*,\#
}

ABSTRACT: The aim of our study was to investigate whether interleukin (IL)-8 activates systemic coagulation after talc pleurodesis in malignant pleural effusion (MPE), and whether levels of IL-8 in plasma are related to early death after talc pleurodesis.

IL-8 and tumour necrosis factor (TNF)- $\alpha$ were measured in samples from 231 MPE patients before and after talc pleurodesis. Whole blood from 31 healthy volunteers was incubated with IL-8, TNF- $\alpha$ and thromboplastin for $3 \mathrm{~h}$ in vitro, and thrombin-antithrombin (TAT) levels were measured. The same stimulation of blood samples was repeated using doses of calibrated talc.

Nine, 12 and 17 patients died within 7, 10 and 15 days respectively. IL-8 was elevated in 102 patients within $48 \mathrm{~h}$, and thrombotic events were observed in six of those patients. Survival correlated inversely with IL-8 at 24 and $48 \mathrm{~h}$, and a significant correlation was also found between IL-8 and TAT. A positive dose-dependent correlation with TAT production was observed when blood was stimulated with IL-8 in vitro. However, there was no significant response to stimulation with talc, as compared with control blood samples.

IL-8 is involved in the activation of coagulation that may occur after talc pleurodesis, and might also be implicated in early death of patients with MPE.

KEYWORDS: Cytokines, inflammation, malignant pleural effusion, talc, thrombin-antithrombin complex

$\mathbf{T}$ here is a growing concern regarding the occurrence of systemic side-effects after intrapleural application of talc for pleurodesis [1-5], and it seems that some of these adverse effects are related to release of proinflammatory mediators in the bloodstream [6-8].

A clear relationship has been established between inflammatory events and the development of thrombovascular disease in several clinical settings [9], and multiple genetic and environmental factors are involved in this relationship [10]. Thus, inflammation plays a key role in venous thromboembolism (VTE), and patients with VTE show higher plasma levels of interleukin (IL)-8 than those without VTE [11-13].

The cytokine IL- 8 is a member of the CXC family, and participates in the inflammatory response [14]. It has been reported that IL-8 production directly correlates with thrombin-antithrombin (TAT) complex [15].

Tumour necrosis factor (TNF)- $\alpha$ is a pleiotropic cytokine that exerts a large variety of biological effects on many cell types. It has been shown to be involved in the pathogenesis of the sepsis syndrome [16] and, according to some studies, it contributes to the pro-coagulant effect by enhancing the expression of tissue factor and inhibiting the fibrinolytic response [17].

Malignant pleural effusions (MPE) are a common complication in many neoplastic diseases. The most effective agent to control MPE is talc [18], but there are concerns about its safety. In the last 25 yrs, there have been several studies reporting cases of acute respiratory distress syndrome after intrapleural talc administration [19-23]. Furthermore, one of the most critical adverse side-effects of talc is related to the incidence of early death following talc pleurodesis. We hypothesised that it could be due to the changes in plasma levels of the inflammatory and coagulation factors produced as a response to an irritant agent, and that pleural talc instillation provokes a systemic dissemination of pro-inflammatory factors that could alter the coagulation/ fibrinolysis balance.

\section{AFFILIATIONS}

*Institute of Biomedicine of Seville (IBIS),

\#Medical-Surgery Unit of Respiratory

Diseases, and

"Haematology Dept, HHUU Virgen

del Rocío, Seville, Spain.

CORRESPONDENCE

F. Rodriguez-Panadero

Unidad Médico Quirúrgica de

Enfermedades Respiratorias

Hospital Universitario Virgen del Rocío

Manuel Siurot s/n 41013 Seville

Spain

E-mail: frpanad@ono.com

Received:

Sept 262008

Accepted after revision:

June 272009

First published online:

July 022009 
The aim of this study was to elucidate the link between inflammation and coagulation after talc pleurodesis for malignant pleural effusions, and to clarify whether thrombotic events activate the inflammatory process or whether, as seems more likely, it is inflammatory mediators that trigger the coagulation cascade via cytokine production. Moreover, we wanted to investigate if early death of patients undergoing talc pleurodesis for MPE was associated with increased levels of inflammation and coagulation markers in plasma.

In the first part of the study, we investigated the link between inflammation and coagulation pathways after talc pleurodesis for MPE. We wanted to clarify if early death of patients undergoing talc pleurodesis for MPE was associated with increased levels of inflammation and coagulation markers in plasma. In the second part, we analysed whether thrombotic events activate the inflammatory process or whether, as seems more likely, it is inflammatory mediators that trigger the coagulation cascade via cytokine production.

In order to obtain evidence for this hypothesis, we measured serial levels of IL-8, TNF- $\alpha$ and TAT complex pre- and post-talc pleurodesis, both in pleural fluid and plasma. However, we stimulated in vitro whole blood samples from healthy volunteers with IL- 8 and TNF- $\alpha$ cytokines, and also with thromboplastin and talc. Then, we measured levels of both inflammation and coagulation mediators.

The conversion of prothrombin into active thrombin is a key event within the coagulation cascade; thrombin is inhibited by antithrombin III resulting in an inactive TAT III complex [24]. Therefore, TAT indicates the activation of the coagulation cascade.

\section{PATIENTS AND METHODS}

\section{Study population}

From July 1993 to September 2007, 231 consecutive patients with MPE (125 females and 106 males, mean (range) age 60 (16-91) yrs) were submitted to thoracoscopic talc poudrage, always following the same technique for thoracoscopy. $4 \mathrm{~g}$ of asbestos-free sterile talc (Steritalc $\mathbb{R}$; Novatech, La Ciotat, France) with undetectable levels of endotoxin as determined by the Limulus amebocyte lysate assay (Toxate; Sigma Aldrich, St Louis, MO, USA) were used. The talc particles had a mean size of $24.5 \mu \mathrm{m}$. All the patients were followed up until death.

For the in vitro study, a second group of 31 volunteers were recruited (19 females and 12 males), with ages ranging from 27 to $50 \mathrm{yrs}$ (mean $30 \mathrm{yrs}$ ). Individuals with chronic disease or any kind of clinically detectable inflammation at the time of recruitment were excluded from the study. Both patients and healthy donors agreed to participate and gave written informed consent. The study was approved by the local Ethics Committee (Hospital Universitario Virgen del Rocio, Seville, Spain).

\section{Blood collection}

Peripheral venous blood was taken from MPE patients at baseline, and 3, 24, 48 and $72 \mathrm{~h}$ after talc application. Each sample was immediately centrifuged and the supernatants were aliquoted, and stored at $-80^{\circ} \mathrm{C}$ for further determinations.
From each healthy volunteer, we collected $5 \mathrm{~mL}$ of fresh whole blood in ethylenediaminetetraacetic acid (EDTA) $K_{3}$ tubes (Vacuette ${ }^{\circledR}$; Bio-one, Greiner, Austria), which was immediately aliquoted into polypropylene tubes for stimulation assay.

\section{Cytokine stimulation}

Whole blood from healthy donors was stimulated in parallel with 62.5 and $250 \mathrm{pg} \cdot \mathrm{mL}^{-1}$ of human IL-8 (R\&D Systems, Minneapolis, MN, USA) or 62.5 and $250 \mathrm{pg} \cdot \mathrm{mL}^{-1}$ of human TNF- $\alpha$ (R\&D Systems). Nonstimulated samples were used as negative controls. The samples were incubated in a humidified atmosphere of $5 \% \mathrm{CO}_{2}$ at $37^{\circ} \mathrm{C}$ for $3 \mathrm{~h}$. After incubation the samples were centrifuged for $5 \mathrm{~min}$ at $1,620 \times g$, and the plasma obtained was aliquoted and frozen at $-80^{\circ} \mathrm{C}$ for further determinations.

We performed a dose-response study by repeating the cytokine stimulation with different doses of both IL-8 and TNF- $\alpha$ as described previously, at concentrations ranging from 31.2 to $1,000 \mathrm{pg} \cdot \mathrm{mL}^{-1}$. The doses of cytokines were chosen within the detection limits of the ELISA (R\&D Systems).

\section{Talc stimulation}

Whole blood from healthy donors was stimulated with 50, 100, $200,500,800$ and $1,600 \mu \mathrm{g} \cdot \mathrm{mL}^{-1}$ of calibrated talc (Steritalc ${ }^{\circledR}$; Novatech). Nonstimulated samples were used as negative controls, and all the samples were processed as explained previously.

\section{Induction of coagulation}

Human placental thromboplastin containing calcium, which is used to activate the coagulation process in vitro (Dade Behring, Marburg, Germany), was added to $1 \mathrm{~mL}$ of whole blood and incubated for $3 \mathrm{~h}$ as explained previously. The doses of thromboplastin assayed ranged from 10 to $200 \mathrm{IU}$.

\section{Inflammation and coagulation mediator determinations}

IL- 8 and TNF- $\alpha$ were measured by ELISA (Quantikine; R\&D Systems), according to the manufacturer's recommendations. The minimum detectable dose of IL-8 ranged $1.5-7.5 \mathrm{pg} \cdot \mathrm{mL}^{-1}$ and for TNF- $\alpha$ ranged $0.5-5.5 \mathrm{pg} \cdot \mathrm{mL}^{-1}$. TAT levels were determined by ELISA with the Enzygnost TAT ${ }_{\circledast}$ kit (Dade Behring) according to the manufacturer's recommendations.

\section{Statistical analysis}

The SPSS software (version 15.0; SPSS, Inc., Chicago, IL, USA) was used. The relationship between survival of patients and markers was studied using both linear and nonlinear regression models. Differences in mediators between patients with early death and those with longer survival were studied using an unpaired t-test, after equal variance analysis. A nonparametric Mann-Whitney U-test was used when distribution of the data did not meet the equal variance criteria. Data was expressed as mean \pm SEM.

\section{RESULTS \\ Early death after talc pleurodesis}

Nine, 12 and 17 patients died within the first 7, 10 and 15 days respectively. Sudden death occurred in four patients, and acute pulmonary embolism was clinically suspected in all. Presence of massive pulmonary embolism was proven in the only patient who was submitted to autopsy. In addition, thrombotic 
events were observed in six of the patients with early death (all of them with increased levels of IL-8 in plasma). Other associated causes of early death were: heart failure in seven patients (three associated with malignant pericardial tamponade), advanced neoplastic disease with bilateral pulmonary involvement in four patients, severe hyponatremia in one and unexplained coma in one. No acute respiratory distress was observed after talc application in our study.

\section{Increased IL-8 plasma levels after talc pleurodesis}

IL-8 dramatically increased in pleural fluid after talc application, and approximately the same increase occurred with TNF- $\alpha$ (table 1). Elevated levels of IL-8 (but not of TNF- $\alpha$ ) were found in plasma of 102 (44\%) patients within the first $48 \mathrm{~h}$ after intrapleural application of talc (table 2). Although the overall differences in IL-8 were not significant, mostly due to dispersion in different types of tumours, there was a clear trend to an increase of IL- 8 at $24 \mathrm{~h}$ in plasma of patients with metastatic lung and breast cancer when compared with baseline levels (84 versus $52 \mathrm{pg} \cdot \mathrm{mL}^{-1}$ and 109 versus $54 \mathrm{pg} \cdot \mathrm{mL}^{-1}$, respectively). This was also the case with tumours of renal origin (312 versus $108 \mathrm{pg} \cdot \mathrm{mL}^{-1}$ ), but the weight of the remaining groups of tumours provoked the lack of statistical difference in the overall study.

An inverse correlation between IL-8 levels and patient survival was observed when we analysed the production of this proinflammatory cytokine in plasma samples 24 and $48 \mathrm{~h}$ after talc pleurodesis (fig. 1). Furthermore, we found significant differences between IL-8 plasma levels in patients who died within the first 15 days after talc pleurodesis compared with those who lived longer. The mean cytokine production at $3 \mathrm{~h}$ following pleurodesis was $80 \pm 34 \mathrm{pg} \cdot \mathrm{mL}^{-1}$ and $55 \pm$ $12 \mathrm{pg} \cdot \mathrm{mL}^{-1}$ in plasma samples of patients who died earlier and those who died after 15 days, respectively (no significant difference). At $24 \mathrm{~h}$, the IL-8 levels were $516 \pm 219 \mathrm{pg} \cdot \mathrm{mL}^{-1}$ and $50 \pm 7 \mathrm{pg} \cdot \mathrm{mL}^{-1}$ in plasma samples of patients who died earlier and those who died after 15 days, respectively $(\mathrm{p}<0.001)$ (fig. 2).

The baseline values of IL-8 in plasma were different in patients with or without early death although the differences did not reach statistical significance: $147 \pm 61 \mathrm{pg} \cdot \mathrm{mL}^{-1}$ in patients dying within the first 15 days compared with $100 \pm 28 \mathrm{pg} \cdot \mathrm{mL}^{-1}$ in those with longer survival. Receiver operating characteristic analysis showed sensitivity equal to 1 and specificity equal to 0.90 for death within the first 7 days, when the cut-off for IL-8 in plasma was $92.5 \mathrm{pg} \cdot \mathrm{mL}^{-1}$ at the $48 \mathrm{~h}$ time-point (area under the curve $=0.937$ ).

We did not find any significant differences when we compared the TNF- $\alpha$ plasma levels with the survival of patients submitted to talc pleurodesis (data not shown).

TAT complex was elevated in plasma of all of the patients who died suddenly or had thrombotic events registered. A significant correlation $(\mathrm{p}<0.02)$ was found between IL-8 and levels of TAT in the plasma of patients at several time-points. In addition, levels of TAT correlated inversely with survival at 24, 48 and $72 \mathrm{~h}$ following talc pleurodesis.

\section{TAT production is related to IL-8 cytokine in vitro stimulation}

Whole blood from healthy volunteers was stimulated with 62.2 and $250 \mathrm{pg} \cdot \mathrm{mL}^{-1}$ of both IL- 8 and TNF- $\alpha$ for $3 \mathrm{~h}$ and TAT levels were then measured. As shown in figure 3, there was a clear relationship between IL- 8 doses and TAT levels $(\mathrm{p}<0.001)$ compared with nontreated samples (controls). This response was higher with the $250-\mathrm{pg} \cdot \mathrm{mL}^{-1}$ dose. Surprisingly, we did not find any significant increase in TAT production when TNF- $\alpha$ was added to the blood samples at either 62.5 or $250 \mathrm{pg} \cdot \mathrm{mL}^{-1}$ doses.

TAT production is activated in a dose-dependent fashion

In order to establish if TAT levels were dose dependent, we repeated the experiment incubating the whole blood samples

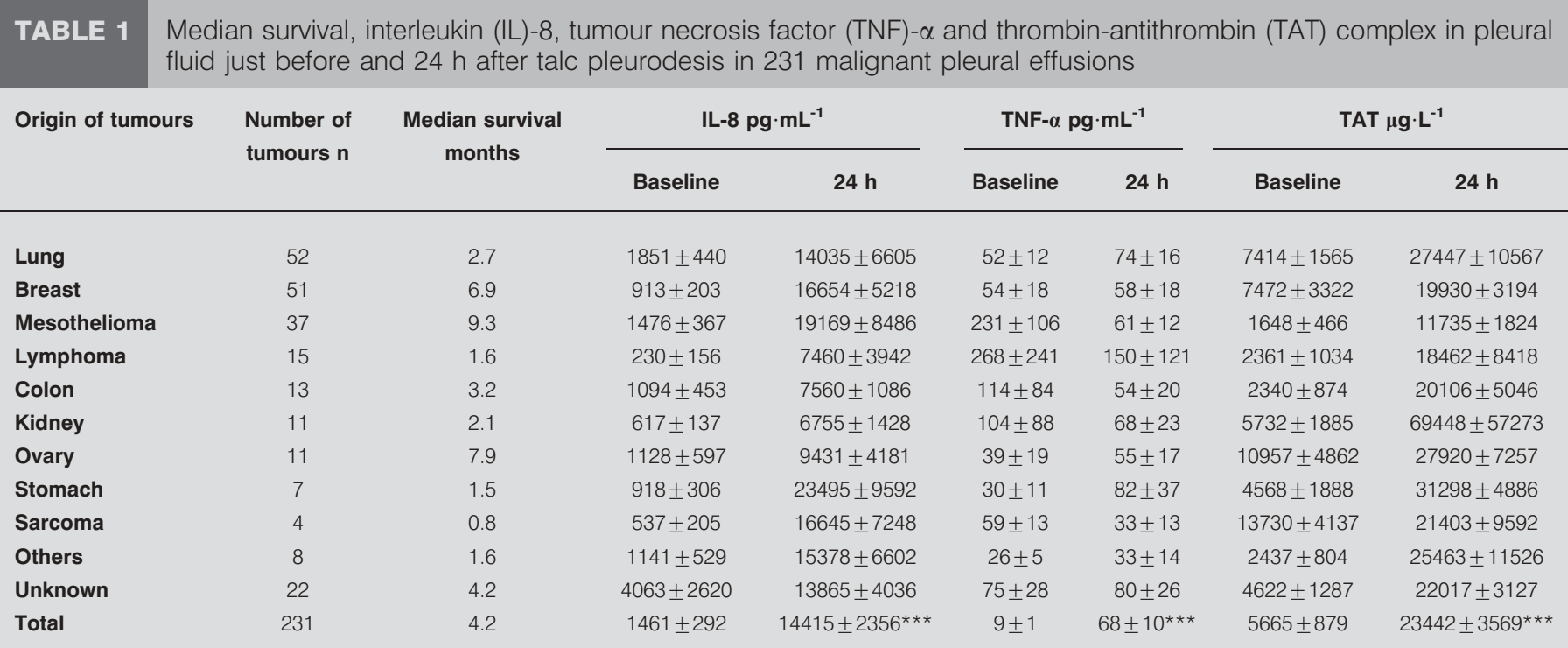




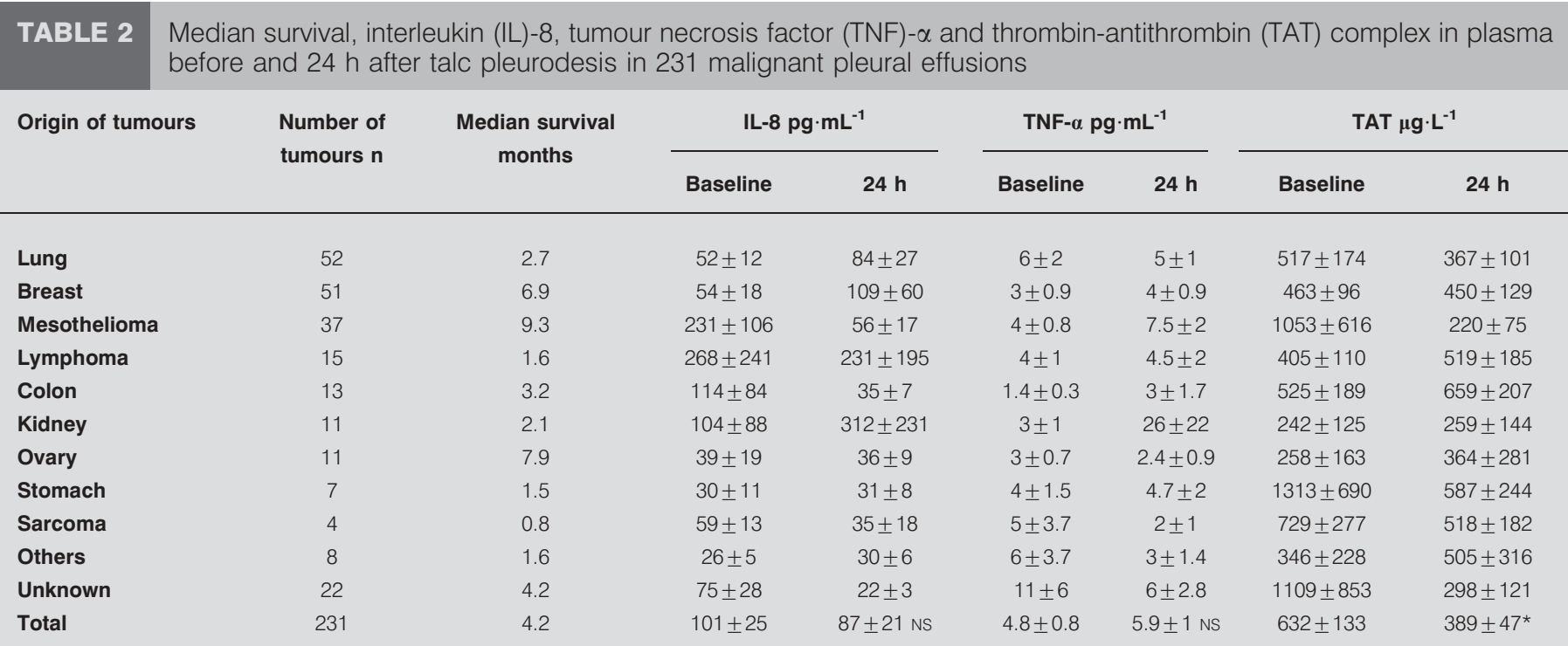
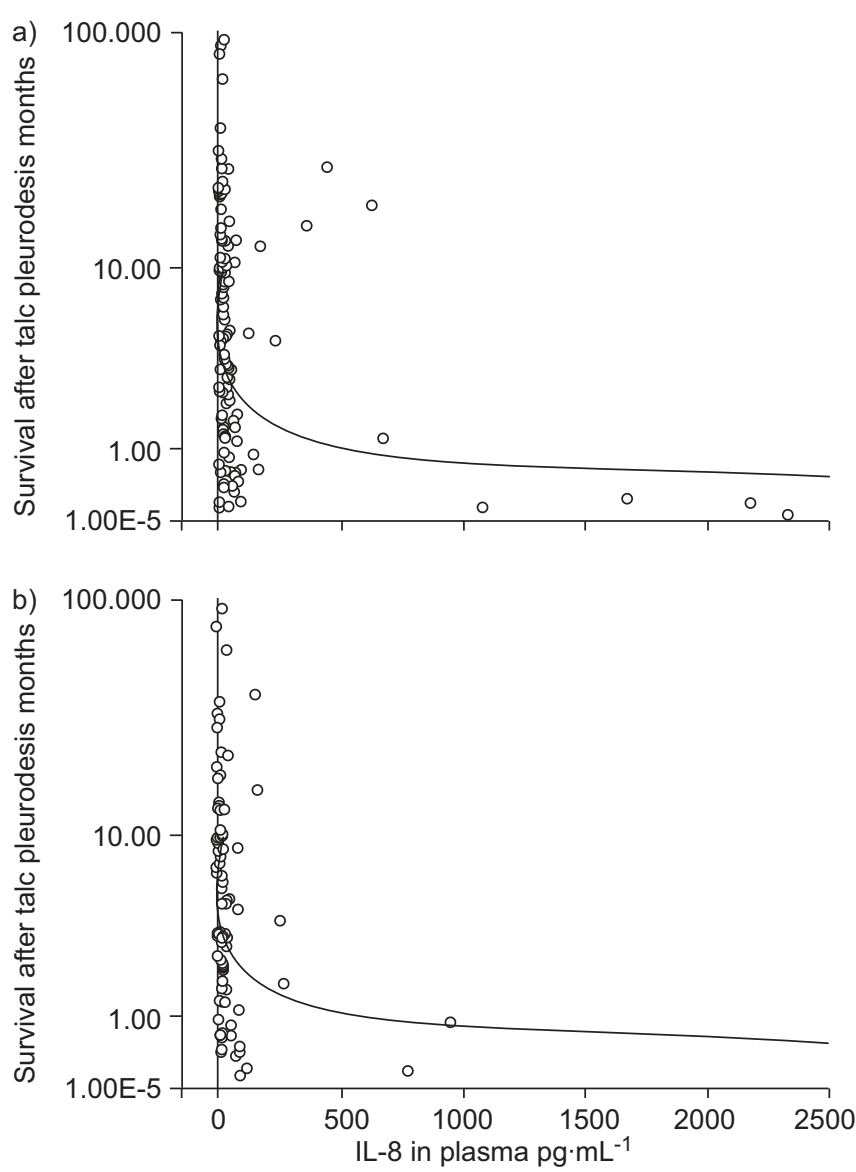

FIGURE 1. Survival and plasma levels of interleukin (IL)-8 from patients with malignant pleural effusion submitted a) 24 and b) $48 \mathrm{~h}$ after talc pleurodesis. The survival of the patients is plotted on a log scale. a) $r=0.39, p<0.001$; $b) r=0.41$, $\mathrm{p}<0.001$ with both IL-8 and TNF- $\alpha$. The doses ranged from 31.2, 62.5, 125,250 and 500 to $1,000 \mathrm{pg} \cdot \mathrm{mL}^{-1}$. A clear dose-dependent response was found in TAT production when IL-8 was added (fig. 4a). However, there was no statistical significance when different doses of TNF- $\alpha$ were assayed (fig. $4 \mathrm{~b}$ ). Nontreated samples did not show any significant TAT production.

\section{EDTA tubes did not alter the activation of coagulation cascade as determined by TAT production}

It is known that EDTA binds calcium ions, thus blocking the coagulation cascade. To verify that this anticoagulant would not interfere in TAT production or in the activation of the coagulation cascade the experiment was repeated adding calcium as calcium chloride solution for the in vitro coagulation

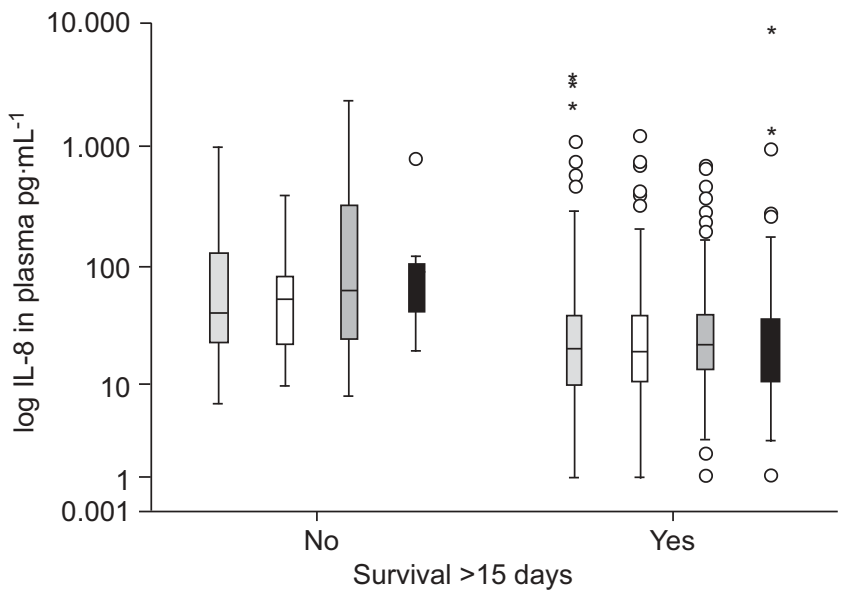

FIGURE 2. Interleukin (IL)-8 levels in plasma of patients with and without early death ( $\leqslant 15$ days) after talc pleurodesis. IL- 8 is depicted as median $\pm 95 \% \mathrm{Cl}$ on a log scale. Circles represent outliers. $\square$ : IL-8 baseline; $\square$ : IL-8 at 3 h; $\square$ : IL-8 at $24 \mathrm{~h} ; \boldsymbol{\square}$ : IL-8 at 48 h. *: $p<0.05$ 


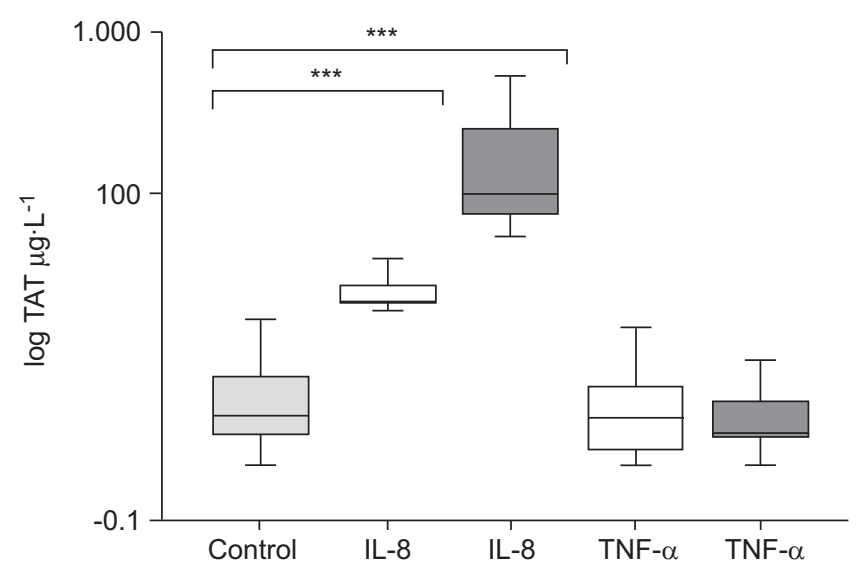

FIGURE 3. Plasma levels of thrombin-antithrombin (TAT) complex when whole blood was stimulated with $62.5 \mathrm{pg} \cdot \mathrm{mL}^{-1}(\square)$ and $250 \mathrm{pg} \cdot \mathrm{mL}^{-1}$ (回) of both interleukin (IL)-8 and tumour necrosis factor (TNF)- $\alpha$ cytokines. Data are plotted on a log scale but refer to absolute concentrations. ${ }^{* \star \star}: \mathrm{p}<0.001$

test $\left(0.025 \mathrm{~mol} \cdot \mathrm{L}^{-1}\right.$; Dade Behring). After incubation, TAT production was measured but no significant differences were found between samples stimulated with or without calcium (fig 5). Once again, samples incubated with TNF- $\alpha$ did not respond to the treatment compared with control samples.

\section{Thomboplastin did not activate cytokine in vitro production in whole blood samples}

To investigate if the inflammatory pathway may be activated by the coagulation cascade, whole blood was incubated with different doses of thromboplastin (Dade Behring) as explained previously. Both IL-8 and TNF- $\alpha$ production were then measured by ELISA and no significant differences between treated and control samples were observed (data not shown).

\section{Talc did not show a significant cytokine or TAT production} in whole blood samples after in vitro stimulation

In order to elucidate if talc would provoke direct production of cytokine and/or TAT, we incubated whole blood samples with $50,100,200,500,800$ and $1,600 \mu \mathrm{g} \cdot \mathrm{mL}^{-1}$ of calibrated talc (Steritalc ${ }^{\circledR}$; Novatech) and nonstimulated samples were used as negative controls. No significant differences were found between treated samples and controls both in IL-8 and TAT production in any of the doses of talc applied in vitro.

\section{DISCUSSION}

For more than $20 \mathrm{yrs}$ our group has been involved in investigating the mechanisms of pleural inflammation, and we have reported a close relationship between inflammation and the coagulation-fibrinolysis balance in the pleural space of patients submitted to talc pleurodesis [25]. Specifically, we found dramatically increased levels of TAT in the pleural fluid of patients with MPE who had a successful pleurodesis [26], but the possible simultaneous activation of coagulation in the systemic circulation could be a life-threatening side-effect. Therefore, we have long been concerned about this particular problem especially as we have observed several cases of massive pulmonary embolism following pleurodesis [27].

The specific aims of our study were to evaluate the relationship between the inflammatory process and the activation of the
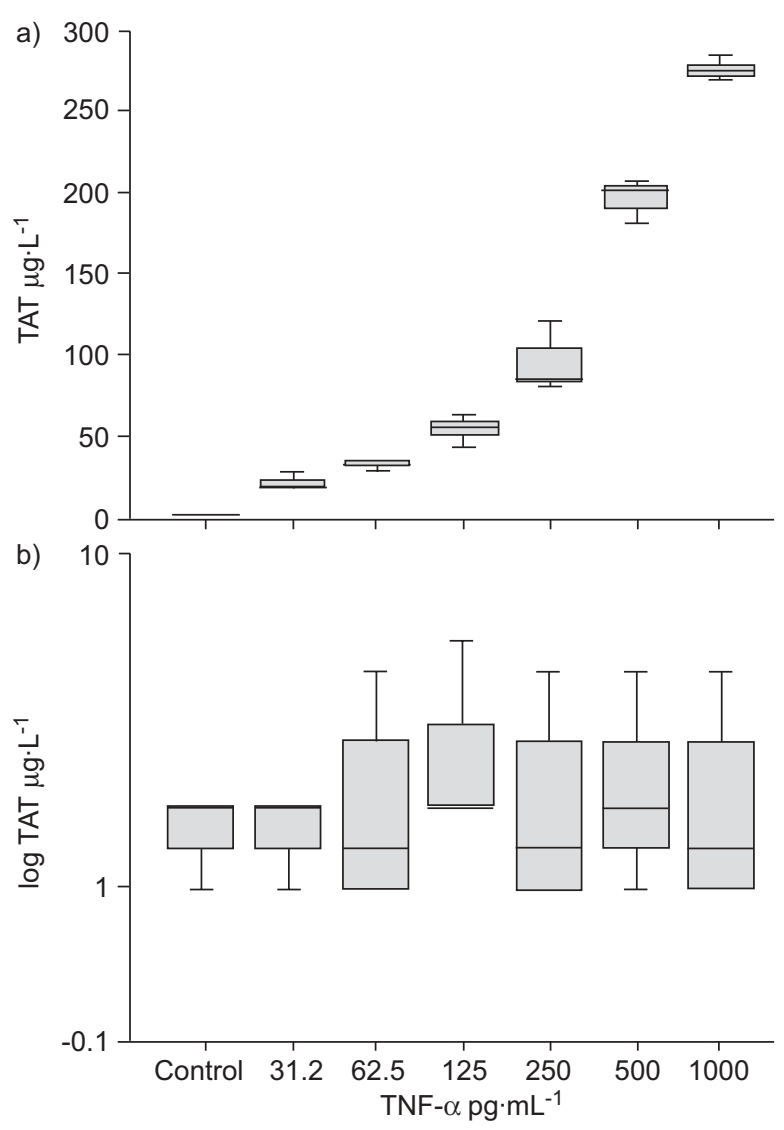

FIGURE 4. Whole blood stimulated with different doses of a) interleukin (IL)-8 and $b$ ) tumour necrosis factor (TNF)- $\alpha$. Thrombin-antithrombin (TAT) levels correlate to IL-8 stimulation at different doses $(p<0.001)$. TAT levels did not show any significant difference between the TNF- $\alpha$ stimulated samples and control. Data are plotted on a log scale but refer to absolute concentrations.

coagulation cascade, and to test whether the inflammatory process is a cause or a result of thrombotic events. In addition, we wanted to find out if there was any relationship between early deaths after talc pleurodesis and plasma levels of proinflammatory markers.

\section{IL-8 and activation of coagulation cascade in the systemic circulation}

Our findings support the idea that IL-8 is involved in the activation of coagulation which may occur after talc pleurodesis. We found that IL- 8 was elevated in the plasma of 102 ( $44 \%$ ) of our patients submitted to talc pleurodesis within the first $48 \mathrm{~h}$, and thrombotic events were observed in six of the patients. In addition, both IL- 8 and TAT were elevated in plasma of these patients at several time-points following talc pleurodesis and a negative correlation was found between plasma levels of IL-8 and survival.

A significant body of evidence has now emerged to support the hypothesis that pro-inflammatory cytokines, which can be released in response to a variety of stimuli, including thoracoscopy without talc application [7], could also play a key role in coagulation activation. An increase in inflammatory mediators such as IL-6, IL-8, monocyte chemotactic protein-1 


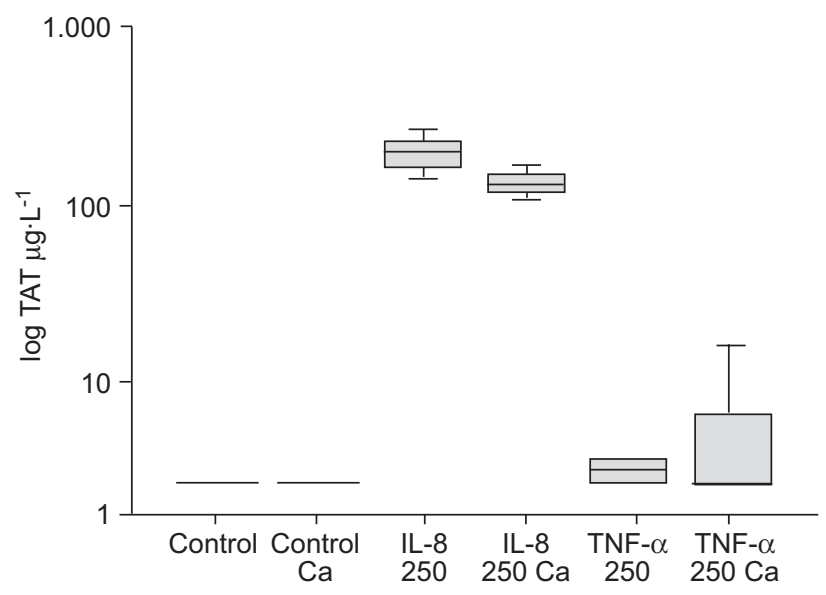

FIGURE 5. Whole blood samples stimulated with or without calcium ions (Ca). There were no significant differences in the thrombin-antithrombin (TAT) levels when doses of $250 \mathrm{pg} \cdot \mathrm{mL}^{-1}$ of the cytokine interleukin (IL)-8 and tumour necrosis factor (TNF)- $\alpha$ were added with calcium ions. Data are plotted on a log scale but refer to absolute concentrations.

and TNF- $\alpha$ has been found in patients with VTE $[12,13]$, and just like pro-inflammatory mediators they may regulate coagulation activation; some products of the clotting cascade may also affect the inflammation process [28]. It has been proposed that coagulation factors, such as tissue factor (TF), Factor VII, Factor X and thrombin, play an important role in inflammation [29]. However, other studies have found no evidence of the role of cytokines in determining the risk of VTE [30], and it remains uncertain whether inflammation is a cause or a result of thrombosis. A possible explanation for the discrepancies in the reported results could be due to differences in the design of the studies. The studies mentioned previously measured the cytokine levels in patients with confirmed venous thrombosis (VT) or prior to endotoxin stimulation but all were conducted in vivo, whereas our study was of whole blood stimulated in vitro. The response found in the in vivo studies could be due to the capacity of the cytokines to interact with each other. However, the increased TAT levels that we found after IL-8 stimulation in vitro suggest a direct implication of this cytokine in coagulation activation. Moreover the correlation was dose dependent. In light of our results, and due to the multifunctional characteristics of this mediator, IL-8 appears to be a key link in the cross-talk between inflammation and coagulation pathways, at least regarding talc pleurodesis. Indeed, we found a clear response of TAT production in plasma samples when whole blood was stimulated with IL-8 (fig. 4a). The increase in TAT levels supports the hypothesis that coagulation is somehow activated by this cytokine, although the molecular mechanism still remains unclear. Interestingly, a study by VAN AKEN et al. [11] reported similar findings. This group reported that patients with VT showed higher IL-8 plasma levels, and concluded that this cytokine is a risk factor for thrombotic disease. TNF- $\alpha$ has been implicated in host defence inflammatory response and pathophysiological processes. A role has been reported for TNF- $\alpha$ in the activation of both coagulation and fibrinolysis [16], but according to our results this cytokine was not able to produce TAT when it was added to whole blood in vitro. This negative response was observed up to a dose of $1,000 \mathrm{pg} \cdot \mathrm{mL}^{-1}$. Therefore, it does not appear that TNF- $\alpha$ participates in the coagulation pathway, at least via TAT production. However, it remains unclear whether TNF- $\alpha$ could be involved in both inflammation and coagulation pathways by activating other factors that might indirectly activate clotting through other cytokines or mediators, or requiring the active participation of the vascular endothelial cells that were obviously absent in our in vitro experiments.

\section{Early death after talc pleurodesis}

Nine, 12 and 17 patients died within the first 710 and 15 days, respectively, following intrapleural application of talc, and sudden death occurred in four of them. Autopsy was performed in one patient and massive pulmonary embolism was reported. As no previous cases of acute respiratory distress were seen in this study, we speculated whether there were more unknown thrombotic events than expected in those patients with short survival.

It is well established that VTE is a common complication in patients with cancer [31, 32]. The interactions between inflammation and coagulation-fibrinolysis balance in the pleural space described by us and others [25, 26, 33], taken together with the finding of elevated levels of IL-8 in plasma of up to $44 \%$ of our patients in the present study, would suggest that after application of the pleurodesis agent IL-8 could disseminate from the inflamed pleural space into the bloodstream, thus activating the systemic coagulation. The association found between high levels of IL-8 in plasma and short survival (fig. 1, table 2) is striking in our study and would support this hypothesis.

It would be interesting to know if our results would also apply to other sclerosants that are frequently used for pleurodesis. We have undertaken a multicentre study on pleurodesis for malignant pleural effusions comparing results of pleurodesis and levels of cytokines in pleural fluid and plasma when either talc doxycycline or tetracycline were used [34]. Our preliminary results indicate that both doxycycline and tetracycline, but especially tetracycline, might provoke increased levels of IL-8 in plasma following the pleurodesis procedure.

Our study has a few limitations. If IL-8 disseminates from the pleural space into the bloodstream after the acute inflammation produced by talc instillation in the pleural cavity, a good correlation between levels in pleural fluid and peripheral venous blood samples would be expected but this was not the case in our series. De novo synthesis of IL-8 in blood following some, so far unexplained, stimuli coming from the pleural space would be another plausible alternative. Further studies involving mRNA investigation for IL-8 and other mediators in peripheral blood samples would be necessary to elucidate this point. Our in vitro study incubating whole blood separately with IL-8 and TNF- $\alpha$ was primarily aimed to elucidate if IL- 8 was able to stimulate per se the production of TAT complex, and we succeeded in this. However, the lack of response to TNF- $\alpha$ stimulation was unexpected and is as yet unexplained. As we have pointed out, the absence of vascular structures (and the possible interaction with endothelial cells) in our in vitro experiment could account for this lack of response. This would also probably be the explanation for the lack of 
significant differences found when whole blood was stimulated with talc.

In conclusion, the main clinical implication of our study was that high plasma IL-8 levels might be a predictor for possible future thrombotic events and/or early death in patients with MPE who are submitted to pleurodesis. Although it reached no statistical significance, our finding that IL-8 levels at baseline were higher in patients with early death (table 2) would support this assertion. Further studies elucidating which mediators regulate the link between inflammatory events and coagulation would have great interest in future target therapies for patients with advanced cancer.

\section{SUPPORT STATEMENT}

This study was supported by Grant FIS 04/0289 from the I.SC. III (Seville, Spain), which was received by F. Rodriguez-Panadero.

\section{STATEMENT OF INTEREST}

None declared

\section{ACKNOWLEDGEMENTS}

We would like to thank E. Martín (Unidad Médico-Quirúrgica de Enfermedades Respiratorias, Hospital Universitario Virgen del Rocío, Sevilla, Spain) for collecting blood samples and for her kind cooperation, and J.L. Valencia (Dept of Haemathology, Hospital Universitario Virgen del Rocío, Sevilla) of the coagulation laboratory for his excellent technical support. We are indebted to all the healthy donors who participated in the study.

\section{REFERENCES}

1 Light RW. Talc for pleurodesis? Chest 2002; 122: 1506-1508.

2 Light RW. Talc should not be used for pleurodesis. Am J Respir Crit Care Med 2000; 162: 2024-2026.

3 Janssen JP. Is thoracoscopic talc pleurodesis really safe? Monaldi Arch Chest Dis 2004; 61: 35-38.

4 Rodriguez-Panadero F, Janssen JP, Astoul P. Thoracoscopy: general overview and place in the diagnosis and management of pleural effusion. Eur Respir J 2006; 28: 409-421.

5 Jannsen JP, Collier G, Astoul P, et al. Safety of pleurodesis with talc poudrage in malignant pleural effusion: a prospective cohort study. Lancet 2007; 369: 1535-1539.

6 Maskell NA, Lee YC, Gleeson FV, et al. Randomized trials describing lung inflammation after pleurodesis with talc of varying particle size. Am J Respir Crit Care Med 2004; 170: 377-382.

7 Froudarakis ME, Klimathianaki M, Pougounias M. Systemic inflammatory reaction after thoracoscopic talc poudrage. Chest 2006; 129: 356-361.

8 Genofre EH, Marchi E, Vargas FS. Inflammation and clinical repercussions of pleurodesis induced by intrapleural talc administration. Clinics 2007; 62: 627-634.

9 Esmon CT. Inflammation and thrombosis. J Thromb Haemost 2003; 1: 1343-1348.

10 Voetsch B, Loscalzo J. Genetic determinants of arterial thrombosis. Arterioscler Thomb Vasc Biol 2000; 24: 216-229.

11 van Aken BE, Reitsma PH, Rosendaal FR. Interleukin 8 and venous thrombosis: evidence for a role of inflammation in thrombosis. Br J Haematol 2002; 116: 173-177.

12 Van Aken BE, Den Heijer M, Bos GM, et al. Recurrent venous thrombosis and markers of inflammation. Thromb Haemostasis 2000; 83: 536-539.
13 Reitsma PH, Rosendaal FR. Activation of innate immunity in patients with venous thrombosis: The Leiden Thrombophilia study. J Thromb Haemost 2004; 2: 619-622.

14 Koch AE, Polverini PJ, Kunkel SL, et al. Interleukin-8 as a macrophage-derived mediator of angiogenesis. Science 1992; 258 1798-1801.

15 Johnson K, Aardeen L, Choi Y, et al. The proinflammatory cytokine response to coagulation and endotoxin in whole blood. Blood 1996; 87: 5051-5060.

16 Van der Poll T, Jansen PM, Van Zee KJ, et al. Tumor necrosis factor- $\alpha$ induces activation of coagulation and fibrinolysis in baboons through an exclusive effect on the p55 receptor. Blood 1996; 88: 9212-9213.

17 Van der Poll $\mathrm{T}$, Büller $\mathrm{HR}$, ten Cate $\mathrm{H}$, et al. Activation of coagulation after administration of tumor necrosis factor to normal subjects. N Engl J Med 1990; 322: 1622-1627.

18 Antony VB, Loddenkemper R, Astoul $\mathrm{P}$, et al. Management of malignant pleural effusions. Official statement of the American Thoracic Society. Am J Respir Crit Care Med 2000; 162: 1987-2001.

19 Rinaldo JE, Owens GR, Rogers RM. Adult respiratory distress syndrome following intrapleural instillation of talc. $J$ Thorac Cardiovasc Surg 1983; 85: 523-526.

20 Bouchama A, Chastre J, Gaudichet A, et al. Acute pneumonitis with bilateral pleural effusion after talc pleurodesis. Chest 1984; 86 795-797.

21 Kennedy L, Rusch VW, Strange C, et al. Pleurodesis using talc slurry. Chest 1994; 106: 342-346.

22 Rehse HD, Aye WR, Florence GM. Respiratory failure following talc pleurodesis. Am J Surg 1999; 177: 437-440.

23 Campos JR, Werebe EC, Vargas FS, et al. Respiratory failure due to insufflated talc. Lancet 1997; 349: 251-252.

24 Pelzer H, Schwarz A, Heimburger N. Determination of human thrombin-antithrombin III complex in plasma with an enzymelinked immunosorbent assay. Thromb Haemostasis 1988; 59: 101-106.

25 Psathakis K, Calderon-Osuna E, Romero-Romero B, et al. The neutrophilic and fibrinolytic response to talc can predict the outcome of pleurodesis. Eur Respir J 2006; 27: 817-821.

26 Rodriguez-Panadero F, Segado A, Martin-Juan J, et al. Failure of talc pleurodesis is associated with increased pleural fibrinolysis Am J Respir Crit Care Med 1995; 151: 785-790.

27 Rodriguez-Panadero F. Current trends in pleurodesis. Curr Opin Pulmonary Medicine 1997; 3: 319-325.

28 Johnson K, Choi Y, DeGroot E, et al. Potential mechanisms for a proinflammatory vascular cytokine response to coagulation activation. J Immunol 1998; 160: 5130-5135.

29 Shoenmarkers SM, Reitsma PM, Spek CA. Blood coagulation factors as inflammatory mediators. Blood Cells Mol Dis 2005; 34: 30-37.

30 Christiansen SC, Naess AI, Cannegieter SC, et al. Inflammatory cytokines as risk factors for a first venous thrombosis: a prospective population-based study. PLoS Med 2006; 3: 1414-1419.

31 Galffy G, Mohamed KA, Dowling PA, et al. Interleukin 8: an autocrine growth factor for malignant mesothelioma. Cancer Res 1999; 15: 367-371.

32 Coussen LM, Werb Z. Inflammation and cancer. Nature 2002; 420 19-26.

33 Agrenius V, Chmielewska J, Widström O, et al. Pleural fibrinolytic activity is decreased in inflammation as demonstrated in quinacrine pleurodesis treatment of malignant pleural effusion. Am Rev Respir Dis 1989; 140: 1381-1385.

34 Romero Falcon A, Montes Worboys A, Arellano Orden E, et al. Comparison in effectiveness and proinflammatory mediators between talc doxycycline and tetracycline for pleurodesis in malignant pleural effusions (MPE). Eur Respir J 2006; 28: Suppl. 50,536 s. 